\title{
Effect of pioglitazone, as antidiabetic agent, on atheroma regression in type 2 diabetic patients: a systematic review and meta- analysis
}

Antoine Fakhry AbdelMassih ${ }^{1 *}$ D, Ahmed Ashraf ${ }^{2}$, Habiba-Allah Ismail², Bassant AbdelAzeim², Ihab Hany Barsoum², Shady Girgis², George Afdal'², Nesrine AbdelAzeim², Peter Afdal², Esraa Menshawey², Rahma Menshawey²,

Kirollos Badr ${ }^{2}$ and Mariem Arsanyous ${ }^{2}$

\begin{abstract}
Background: Pioglitazone's role in the induction of atheroma regression in diabetics was suggested by several RCT. The aim of our study was to evaluate this role through a systematic review of all RCT conducted on this subject.

Methods: Literature was searched for relevant studies. We included all RCT that compared pioglitazone versus other antidiabetic agents. Mean differences of either AV or CIMT, HbA1C, HDL, and LDL between the two groups were used to assess the effect of pioglitazone versus alternative therapies.

Results: Six RCT were included with a total of 1180 patients. Pioglitazone was significantly superior to glimepiride and gliclazide in improving IMT. No significant difference was observed in overall AV, HbA1C, and LDL.

Conclusion: The latter findings confirm that anti-atheroma action of pioglitazone is not achieved through its antiglycemic or antidyslipidemia effects, but probably through a DNA-mediated effect, and may lead to its repurposing for reversal of organ fibrosis.
\end{abstract}

Keywords: Pioglitazone, Antiatherogenic effect, Regenerative medicine, Metabolic syndrome, Type 2 diabetes mellitus

\section{Background}

Regenerative medicine is a relatively new term in modern medicine that has flourished over the last four decades. It includes any drug or intervention that can induce regeneration of human cells, tissues, and organs with the intention of reestablishing normal functionality. The main focus of regenerative medicine was organ and stem cell transplantation [1]. However, new bodies of evidence suggest the increasing role of drugs as part of regenerative medicine. Regenerative pharmacology suggests that drugs might be used to induce complete

\footnotetext{
* Correspondence: antoine.abdelmassih@kasralainy.edu.eg

${ }^{1}$ Pediatric Cardiology Department, Cairo University, Cairo, Egypt

Full list of author information is available at the end of the article
}

regeneration of certain organs by exerting effects on nuclei and deoxyribonucleic acid (DNA) [2]. Recently, Afdal et al. suggested a potential role of peroxisome proliferator-activated receptor (PPAR) $\gamma$ agonists in the induction of regression pulmonary vascular disease, which might be regarded as a breakthrough to eliminate, with time, the need for heart-lung transplantation $[3,4]$. PPAR $\gamma$ agonists, especially pioglitazone, act by epigenetic mechanisms to alter DNA expression and therefore play a crucial role in triggering organ reverse remodeling at multiple levels $[5,6]$. This effect has encouraged many scientists over the years to study the effect of pioglitazone on atheroma regression. Atheroma is the key lesion in macrovascular disease seen in patients with metabolic 
syndrome [7-12]. Along with its cardiac and cerebral sequelae, it is regarded as the number one cause of death worldwide. The estimates from the World Health Organization suggest that up to $31 \%$ of deaths worldwide are atheroma related [13]. The primary outcome parameter of this study was to use the totality of previous randomized clinical trials on the effect of pioglitazone on atheroma regression, by quantitatively evaluating its potential ability to do so through its effect on atheroma volume (AV), and carotid intima media thickness (CIMT), as well determine through which secondary outcome parameters pioglitazone was inducing such changes by determining any correlation between its use and glycated hemoglobin (HbA1c), low-density lipoproteins (LDL), and high-density lipoprotein (HDL) levels.

\section{Materials and methods}

This systematic review has been conducted in agreement with the guidelines of the PRISMA (Preferred Reporting Items for Systematic Reviews and Meta-Analysis) statement [14].

\subsection{Data search}

An electronic search for relevant studies was performed using EMBASE, Medline, and the Cochrane Central
Register (January1990 to January 2019) of Controlled Trials.

\subsection{Study selection criteria \\ 2.2.1 Inclusion criteria}

Population: diabetic and non-diabetic patients with carotid/coronary atheroma

Intervention: pioglitazone \pm standard therapy/control: placebo or no treatment \pm standard therapy/outcomes: atheroma volume by intravascular ultrasound (IVUS) or by carotid intima media thickness/study design: randomized controlled trials (RCT) [15]

\subsubsection{Exclusion criteria}

Any study that failed to tackle the primary outcome parameters or was lacking the patients' characteristics

\subsection{Data extraction}

All data from eligible studies were extracted by two independent investigators according to a standard protocol. Recorded data variables included trial name, year of publication, country of origin, eligibility criteria, baseline characteristics, duration of follow-up, and number of participants. Other variables considered were standardized mean difference of atheroma volume or carotid

Table 1 Summary statistics of the studied populations in the 6 selected studies

\begin{tabular}{|c|c|c|c|c|c|c|}
\hline Trial & $\begin{array}{l}\text { Steven E. Nissen } \\
\text { et al. [8] }\end{array}$ & $\begin{array}{l}\text { Mazzone } \\
\text { et al. [12] }\end{array}$ & $\begin{array}{l}\text { Kanazawa } \\
\text { et al. [11] }\end{array}$ & $\begin{array}{l}\text { Nakayama, } \\
\text { et al. [10] }\end{array}$ & $\begin{array}{l}\text { Park } \\
\text { et al. [9] }\end{array}$ & $\begin{array}{l}\text { Ogasawara, } \\
\text { et al. [7] }\end{array}$ \\
\hline Publication year & 2008 & 2006 & 2010 & 2010 & 2007 & 2009 \\
\hline Country & $\begin{array}{l}\text { North and South } \\
\text { America }\end{array}$ & USA Chicago & Japan & Japan & Korea & Japan \\
\hline Active/control & $\begin{array}{l}\text { Pioglitazone vs } \\
\text { glimepiride }\end{array}$ & $\begin{array}{l}\text { Pioglitazone } \\
\text { vs glimepiride }\end{array}$ & $\begin{array}{l}\text { Pioglitazone } \\
\text { vs metformin }\end{array}$ & $\begin{array}{l}\text { Pioglitazone vs } \\
\text { standard therapy } \\
\text { (control) }\end{array}$ & $\begin{array}{l}\text { Pioglitazone } \\
\text { vs gliclazide } \\
\text { (control) }\end{array}$ & $\begin{array}{l}\text { Pioglitazone vs } \\
\text { group with their } \\
\text { previous antidiabetic } \\
\text { regimen (control) }\end{array}$ \\
\hline Sample size & $\begin{array}{l}543 \text { patients with } \\
\text { type } 2 \text { diabetes and } \\
\text { coronary disease }\end{array}$ & $\begin{array}{l}462 \text { adults } \\
\text { with type } 2 \\
\text { diabetes }\end{array}$ & $\begin{array}{l}55 \text { patients with } \\
\text { type } 2 \text { diabetes } \\
\text { mellitus }\end{array}$ & $\begin{array}{l}26 \text { patients with } \\
\text { stable angina and } \\
\text { type } 2 \text { diabetes }\end{array}$ & $\begin{array}{l}40 \text { patients } \\
\text { with type } 2 \\
\text { diabetes }\end{array}$ & $\begin{array}{l}54 \text { patients with type } \\
2 \text { diabetes and stable } \\
\text { angina pectoris }\end{array}$ \\
\hline Age in years (mean $\pm S D$ ) & $60 \pm 9.4 P / 59.7 \pm 9.1 C$ & $\begin{array}{l}58.9 \pm 7.8 \mathrm{P} / \\
59.8 \pm 8.1 \mathrm{C}\end{array}$ & $\begin{array}{l}67 \pm 10 \mathrm{P} / 66 \\
\pm 10 \mathrm{M}\end{array}$ & $\begin{array}{l}67.0 \pm 7.5 P / 63.0 \\
\pm 10.5 C\end{array}$ & $\begin{array}{l}63.1 \pm 7.2 \mathrm{P} / \\
64.2 \pm 7.1 \mathrm{C}\end{array}$ & $\begin{array}{l}68.6 \pm 7.9 P / 66.8 \\
\pm 8.1 C\end{array}$ \\
\hline Baseline $\mathrm{HbA} 1 \mathrm{c}, \%$ (mean $\pm \mathrm{SD}$ ) & $7.4 \pm 1 \mathrm{P} / 7.4 \pm 1 \mathrm{C}$ & $\begin{array}{l}7.44(1.01) \mathrm{P} / \\
7.36(0.95) \mathrm{G}\end{array}$ & $\begin{array}{l}7.9 \pm 1.7 \mathrm{P} / 7.9 \\
\pm 1.3 \mathrm{M}\end{array}$ & $\begin{array}{l}6 \pm 1.3 P / 5.4 \\
\pm 0.9 C\end{array}$ & $\begin{array}{l}9.0 \pm 2.3 P / 8.8 \\
\pm 2.2 \mathrm{C}\end{array}$ & $\begin{array}{l}7.17 \pm 0.72 P / 6.80 \\
\pm 0.85 C\end{array}$ \\
\hline $\begin{array}{l}\text { Baseline fasting glucose, } \\
\mathrm{mg} / \mathrm{dL} \text { (mean } \pm \mathrm{SD})\end{array}$ & $\begin{array}{l}147.2 \pm 41 P / 148 \\
\pm 43.4 C\end{array}$ & $\begin{array}{l}149.2(48.3) \mathrm{P} / \\
148.2(44.7) \mathrm{C}\end{array}$ & Not supplied & $\begin{array}{l}103 \pm 12 P / 99 \\
\pm 12 C\end{array}$ & $\begin{array}{l}9.85 \pm 1.27 \mathrm{P} / \\
9.51 \pm 0.96 \mathrm{C}\end{array}$ & $\begin{array}{l}139.3 \pm 35.3 P / 129.2 \\
\pm 27.0 \mathrm{C}\end{array}$ \\
\hline $\mathrm{BMI}($ mean $\pm \mathrm{SD})$ & $\begin{array}{l}32.1 \pm 5.3 P / 32 \\
\pm 5.2 \mathrm{C}\end{array}$ & $\begin{array}{l}32.2 \pm 5.1 \mathrm{P} / \\
32.0 \pm 5.1 \mathrm{C}\end{array}$ & $\begin{array}{l}22.0 \pm 2.3 P / 24.9 \\
\pm 3.7 C\end{array}$ & Not supplied & $\begin{array}{l}24.3 \pm 4.1 P / \\
24.1 \pm 3 C\end{array}$ & $\begin{array}{l}23.8 \pm 3.0 \mathrm{P} / 24.1 \\
\pm 2.1 \mathrm{C}\end{array}$ \\
\hline Median follow-up & 18 months & 72 weeks & 12 months & 6 months & 3 months & 6 months \\
\hline \multicolumn{7}{|c|}{ Changes from baseline to year 1 or final visit } \\
\hline $\begin{array}{l}\text { HbA1C post ttt (diabetics/ } \\
\text { non-diabetics) (mean } \pm \text { SD) }\end{array}$ & $6.9 \pm 0.9 P / 7 \pm 1 C$ & Not supplied & $\begin{array}{l}7.1 \pm 1.2 \mathrm{P} / 7.1 \\
\pm 1.1 \mathrm{C}\end{array}$ & $\begin{array}{l}5.8 \pm 0.8 P / 5.3 \\
\pm 0.8 C\end{array}$ & $\begin{array}{l}7.1 \pm 1.3 \mathrm{P} / 7.1 \\
\pm 1.2 \mathrm{C}\end{array}$ & $\begin{array}{l}6.50 \pm 1.05 P / 6.81 \\
\pm 0.87 C\end{array}$ \\
\hline $\begin{array}{l}\text { Fasting glucose post ttt } \\
\text { (diabetics/non-diabetics) } \\
\text { (mean } \pm \text { SD) }\end{array}$ & $\begin{array}{l}139.3 \pm 29.1 \mathrm{P} / \\
147.9 \pm 33.8 \mathrm{C}\end{array}$ & Not supplied & Not Supplied & $\begin{array}{l}97 \pm 14 P / 102 \\
\pm 21 C\end{array}$ & $\begin{array}{l}7.95 \pm 1.03 \mathrm{Pl} \\
7.47 \pm 0.74 \mathrm{C}\end{array}$ & $\begin{array}{l}113.7 \pm 28.9 P / 137.8 \\
\pm 39.8 \mathrm{C}\end{array}$ \\
\hline
\end{tabular}




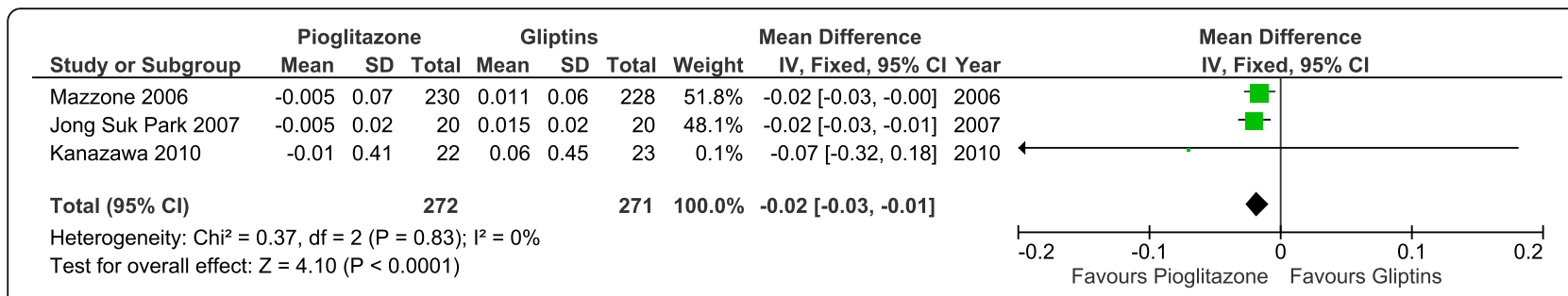

Fig. 1 Effect of pioglitazone vs. other antidiabetic agents on CIMT. CIMT, carotid intima media thickness; Cl, confidence interval; $P^{2}$, heterogeneity; IV, intravitreal; SD, standard deviation; Z, overall effect

intima media thickness, glycated hemoglobin (HbA1C), low-density lipoproteins (LDL), and high-density lipoproteins (HDL) in recipients of pioglitazone vs. controls (recipients of other antidiabetic drugs). We assessed study quality using the Cochrane risk-of-bias algorithm.

\subsection{Statistical analysis}

Mean differences in atheroma volume by intravascular ultrasound or carotid intima media thickness (CIMT) were all included as primary outcome parameters for comparison between pioglitazone versus control. We calculated the standardized mean difference and their corresponding $95 \%$ CIs. For the statistical analysis, we used a random-effects model and explored for sources of inconsistency $\left(I^{2}\right)$ and heterogeneity. We considered study-level estimates to be heterogeneous if the $x^{2}$ test was significant $(P<0.05)$. The Cochrane Collaborations Review Manager Software Package (RevMan 5.3) was used for this meta-analysis. Tests for heterogeneity, as well as $Z$ test and $P$ values, were determined for secondary outcome parameters including HbA1c, LDL, and HDL.

\section{Results}

\subsection{Main findings}

The literature review identified 10 studies that were deemed suitable for detailed assessment, four of which were excluded. Koshiyama et al.'s [16] study was excluded due to the lack of patient characteristics which might induce a major selection bias. Nozue et al.'s [17] series was excluded due to lack of comparison between a pioglitazone group and a control group; comparison was conducted between a diabetes mellitus (DM) group and a non-DM group. Finally, Dormandy et al. and Liu et al. $[18,19]$ were excluded due to different clinical endpoints or outcome parameters than those previously mentioned, namely CIMT and atheroma volume by IVUS.

Six studies were ultimately included with a totality of 1990 patients.

Patient characteristics have been summarized for each study in Table 1.

Pioglitazone use showed a statistically significant superior effect on CIMT compared to other antidiabetic therapies $(P<0.001)$ (Fig. 1$)$. In contrast, pioglitazone did not achieve a superior effect in decreasing atheroma volume as assessed by IVUS (Fig. 2). Furthermore, examination of secondary outcome parameters revealed no superior effect of pioglitazone use in reduction of HbA1c and LDL levels $(P=0.11$ and $P=0.97$ respectively $)$ (Figs. 3 and 4). HDL levels were significantly improved with the use of pioglitazone $(P<0.00001)$ (Fig. 5). This strongly suggests that the means through which pioglitazone affects carotid intima media thickness is by an HDL-mediated anti-inflammatory and antifibrotic function.

\subsection{Bias assessment of the quality of included RCTs}

Any potential bias has been discussed in Fig. 6, according to the revised Cochrane risk-of-bias tool for randomized trials [20]. The main limitation that can interfere with the credibility of these results is the lack of

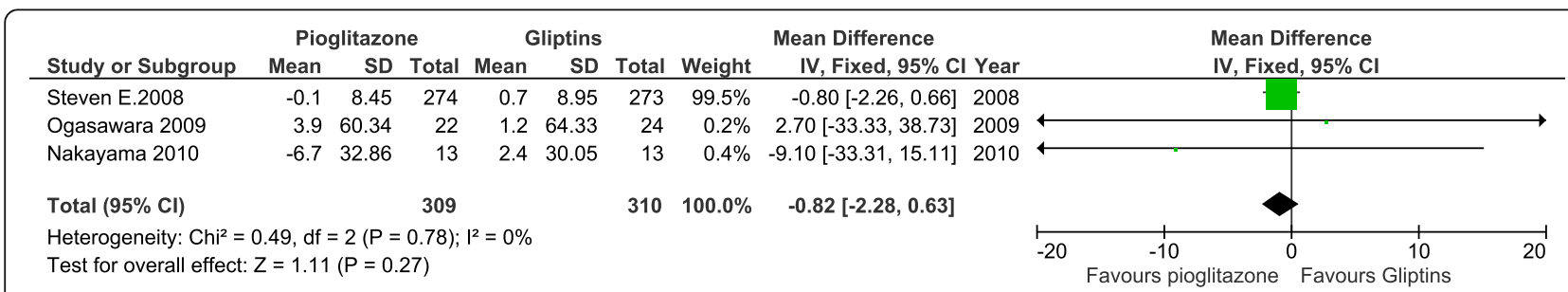

Fig. 2 Effect of pioglitazone vs. other antidiabetic agents on atheroma volume. Cl, confidence interval; $P^{2}$, heterogeneity; IV, intravitreal; SD, standard deviation; $Z$, overall effect 


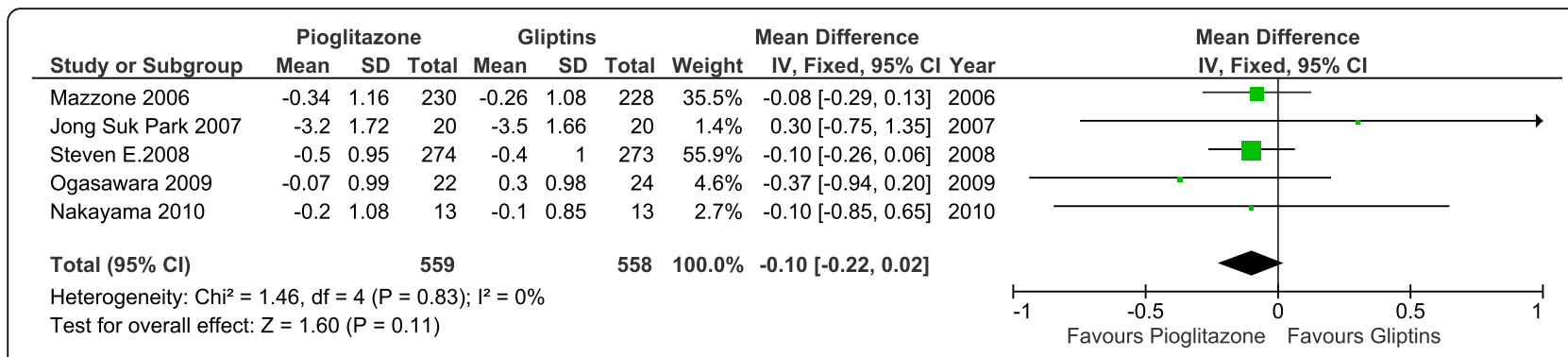

Fig. 3 Effect of pioglitazone vs. other antidiabetic agents on $\mathrm{HbA1c}$. Cl, confidence interval; HbA1c, glycated hemoglobin; $P^{2}$, heterogeneity; IV, intravitreal; SD, standard deviation; Z, overall effect

uniformity of outcome parameters assessed in the different studies. Three studies only assessed the CIMT [9, $11,12]$, while the other three assessed the AV $[7,8,10]$. Kanazawa et al. did not assess all the secondary outcome parameters [11]. Finally, yet importantly, Mazzone et al. did not assess LDL [12]. Another important source of bias is the lack of variability of races in the included trials. Most of the trials have been performed in Asian populations; the atheroma regression by pioglitazone observed can vary according to races.

\section{Discussion}

Since their first discovery as antiglycemic drugs in 1990, glitazones have gained interest as potential pharmacological targets for other disorders. They have multiple DNA-mediated effects that make them potential antifibrotic agents. Atheroma represents an important biologic model of fibrotic pathology, comprising diseases such as liver cirrhosis, pulmonary vascular disease, pulmonary fibrosis, and finally age-related male infertility and androgen decline due to under-studied vascular and atherosclerotic changes within the testicular tissue [21]. The potential regenerative therapeutic ability of pioglitazone on atheroma regression will be useful to patients with coronary or cerebrovascular diseases, as well give hope to diseased patients suffering from the aforementioned disorders [22-24].

In our study, we have examined the role of pioglitazone as an antidiabetic agent for the induction of atheroma regression in diabetic patients, which was demonstrated in six series comprising a total of $1180 \mathrm{pa}-$ tients who received pioglitazone vs. other antidiabetic agents. Our study has proved a statistically significant difference between pioglitazone and other alternative therapies, namely glimepiride and gliclazide, in decreasing CIMT as shown in Fig. 1. This superior effect could not be proved on AV by IVUS as shown in Fig. 2.

IMT is the earliest lesion to develop in the context of atherosclerosis, which could explain why pioglitazone has an effect on CIMT rather than atheroma volume. An established atheroma can be more resistant to any antifibrotic treatment, thus needing more time to achieve palpable results. Two out of the three studies that assessed the effect of pioglitazone had a relatively short duration, namely Ogasawara et al. and Nakayama et al. $[7,10]$. More effect could have been achieved if the period of the clinical trial would have been extended [25].

The exact mechanisms by which pioglitazone reverse atheroma and fibrosis are not completely understood.

In our study, pioglitazone achieved no superior effect compared to other antidiabetic agents in the control of hyperglycemia or in reducing LDL lipoproteins. This suggests that pioglitazone operates through other mechanisms to allow for the regression of atherosclerosis.

Endothelial cell (EC) dysfunction stands as a cornerstone in the pathogenesis of atherosclerosis. The function of ECs might be compromised by increased shear stress, dyslipidemia, inflammation, and many other factors [26]. The disturbed function of ECs might induce

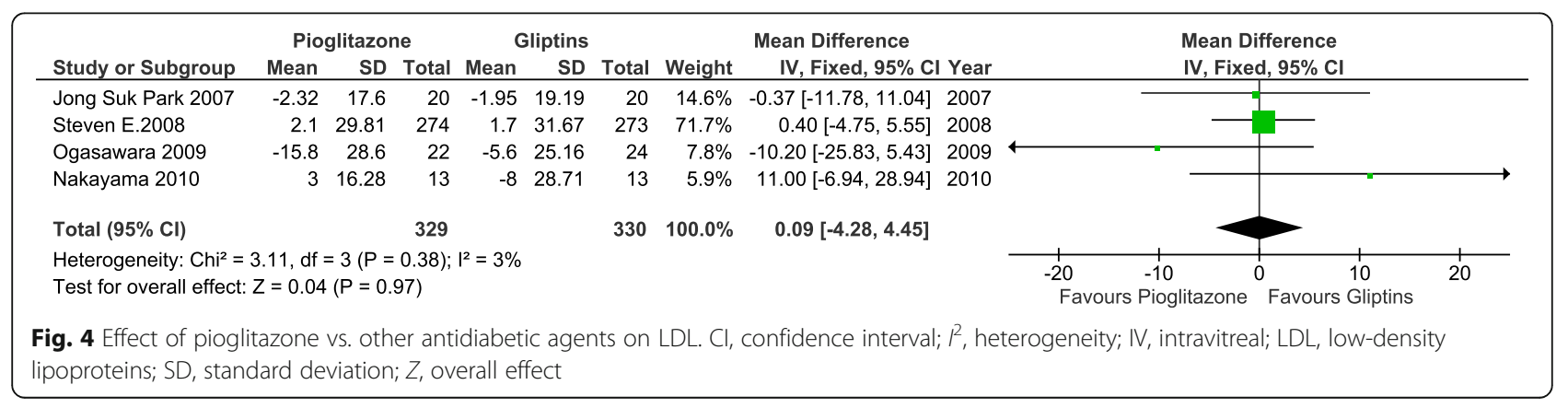




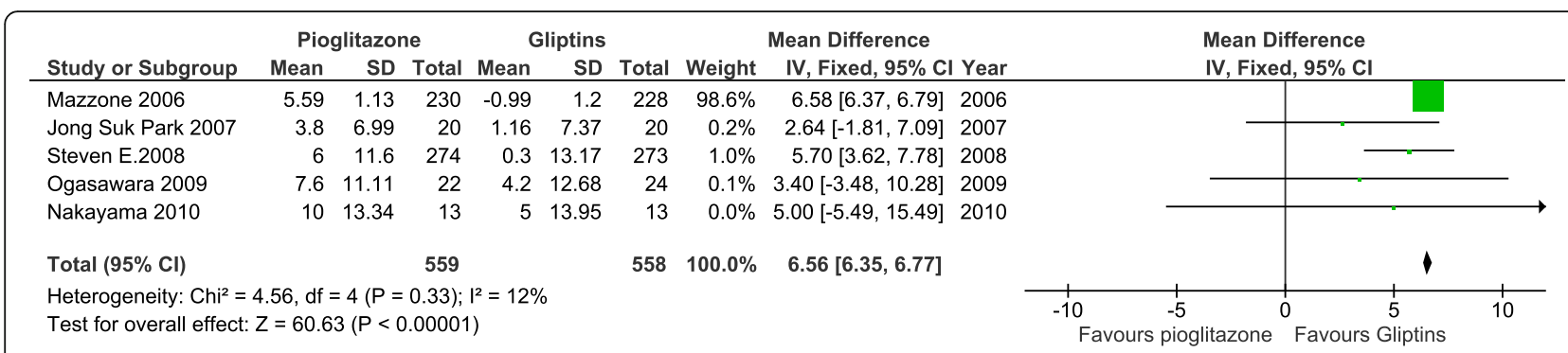

Fig. 5 Effect of pioglitazone vs. other antidiabetic agents on HDL. Cl, confidence interval, $I^{2}$ heterogeneity, IV, intravitreal; HDL, high-density lipoproteins; SD, standard deviation; Z, overall effect

the release of different injurious agents such as transforming growth factor (TGF), fibroblast growth factor (FGF), and vascular cell adhesion molecule (VCAM). These key players and other molecular targets can be directly downregulated by the epigenetic mechanisms exerted by pioglitazone [26, 27].

Furthermore, the correlation between pioglitazone use and HDL levels suggests that it is through an HDLmediated mechanism that pioglitazone is able to achieve changes in atheroma volume and carotid intimal media thickness. This finding is supported by other studies which found a strong association between elevated non-HDL levels and other body mass parameters with CIMT in particular [18]. The study suggests that atherosclerotic pathology and its progression is more so factored by CIMT rather than plaque burden, and that this effect is mediated by cholesterol levels [18]. Through its antiatherogenic effects, by means of a reverse cholesterol transport pathway, elevated levels of HDL are an established method to decrease the risk of cardiovascular injury. The search for new and effective drugs for this purpose continues, and of particular interest are drugs that can increase endogenous levels of HDL, such as pioglitazone, rather than the use of exogenous substances that only mimic the effect of HDL [19]. Kardassis and colleagues showed that glitazones can improve the expression of HDL genes which go in agreement with our findings [28].

Decreased HDL levels are an established part of every level of atheroma pathophysiology whereby the mechanisms of (1) inhibiting monocyte adhesion to endothelial cells at sites of plaque formation, (2) promoting NO production which suppresses proliferation of the plaque, (3) promoting fibrinolysis, and (4) preventing intra-plaque hemorrhage and many other pleiotropic effects are lost in the setting of decreased HDL levels [19].

\section{Conclusion}

The role of pioglitazone in the induction of atheroma regression in diabetic patients has been confirmed through our series. This effect seems to be independent of the antiglycemic and antidyslipidemic effects of glitazones. Glitazones might operate through decreasing the yield of vascular pro-inflammatory molecules or through increasing the expression of HDL genes as proven by Kardassis et al. Longer duration studies are needed to consolidate the beneficial effects of glitazones on atheroma volume. Also, new clinical trials exploring pioglitazone effects against statins and new antidiabetic agents should be initiated to consolidate the role of pioglitazone. Such proof may help in re-tailoring the therapeutic protocols of diabetic patients with atherosclerosis, making abandoned glitazones as a first option again. Also, atheroma is an important biological model for organ fibrosis that is encountered in many other disorders, such as liver cirrhosis and pulmonary vascular disease. The confirmed effect offers a new hope to many patients on organ transplantation waiting list and officially unleashes the potential of glitazones as members of regenerative pharmacology.

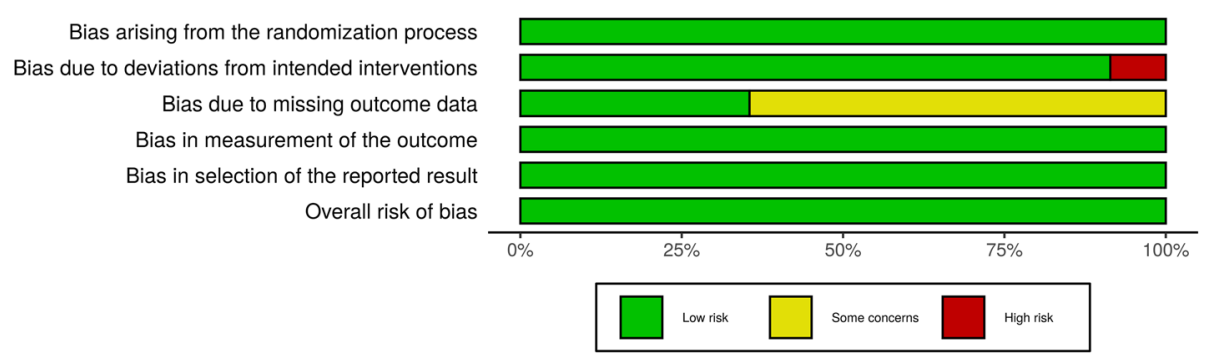

Fig. 6 Bias assessment of included studies 


\section{Abbreviations}

AV: Atheroma volume; CIMT: Carotid intima media thickness; DNA: Deoxyribonucleic acid; DM: Diabetes mellitus; HbA1C: Glycated hemoglobin; HDL: High-density lipoprotein; IVUS: Intravenous ultrasound; LDL: Low-density lipoprotein; NO: Nitric oxide; PPAR: Peroxisome proliferatoractivated receptors; RCT: Randomized controlled trials

\section{Acknowledgements}

To our families who are bearing the weight of our sacrifice of time to our patients. If our families were not understanding to the depth of our struggle, we would have never been able to keep the same level of dedication to our patients. To our students that we involve in each step of our researches to make them flourish in this field and take the lead the soonest the possible.

\section{Authors' contribution}

AFA and $\mathrm{HI}$ contributed to the conception and design of the work. AA, BA, $I B$, and SG contributed significantly to the acquisition of data. AFA, AA, HI, $B A, I B, S G, G A, N A, P A, E M, R M, K B$, and MA contributed to the analysis and interpretation of data. R.M contributed to the drafting and revision of the manuscript. All authors have approved the submitted version. All authors have agreed both to be personally accountable for the author's own contributions and to ensure that questions related to the accuracy or integrity of any part of the work, even ones in which the author was not personally involved, are appropriately investigated, resolved, and the resolution documented in the literature.

\section{Funding}

This research received no specific grant from any funding agency or commercial or not-for-profit sectors.

\section{Availability of data and materials}

Not applicable.

\section{Ethics approval and consent to participate}

Not applicable

\section{Consent for publication}

Not applicable

\section{Competing interests}

The authors declare that they have no competing interests

\section{Author details}

${ }^{1}$ Pediatric Cardiology Department, Cairo University, Cairo, Egypt. ${ }^{2}$ Research accessibility Team, Students and Interns Research Program, Cairo University, Cairo, Egypt

Received: 6 October 2020 Accepted: 8 January 2021

Published online: 03 February 2021

\section{References}

1. Gabriels C et al (2014) A different view on predictors of pulmonary hypertension in secundum atrial septal defect. Int J Cardiol 176:833-840

2. Ng-Blichfeldt, J. P., Gosens, R., Dean, C., Griffiths, M. \& Hind, M. Regenerative pharmacology for COPD: breathing new life into old lungs. Thorax 1-8 (2019). doi:https://doi.org/10.1136/thoraxjnl-2018-212630

3. Afdal P, AbdelMassih AF (2018) Is pulmonary vascular disease reversible with PPAR $\gamma$ agonists? Microcirculation 25:1006-1012

4. Afdal, P. et al. Peroxisome proliferator-activated receptor agonists and reversal of vascular degeneration through DNA repair, a step toward druginduced regenerative medicine. Cardiovasc. Endocrinol. Metab. Publish Ah, 14-17 (2020). ahead of print

5. Sheikhpour M, Abolfathi H, Khatami S, Meshkani R, Barghi TS (2020) The interaction between gene profile and obesity in type 2 diabetes: a review. Obes Med. 18:100197

6. Kakkar, M. et al. Exploration of combined effect of peroxisome proliferator activated receptor (PPAR) agonist and retinoic acid receptor (RAR) agonist on experimental models of inflammation in rats. Obes Med. 100260 (2020). doi:https://doi.org/10.1016/j.obmed.2020.100260
7. Ogasawara D et al (2009) Pioglitazone reduces the necrotic-core component in coronary plaque in association with enhanced plasma adiponectin in patients with type 2 diabetes mellitus. Circ J. 73:343-351

8. Nissen SE et al (2008) Comparison of pioglitazone vs glimepiride on progression of coronary atherosclerosis in patients with type 2 diabetes: the PERISCOPE randomized controlled trial. JAMA 299:1561-1573

9. Park JS et al (2007) The effects of pioglitazone on cerebrovascular resistance in patients with type 2 diabetes mellitus. Metabolism. 56:1081-1086

10. Nakayama T et al (2010) Pioglitazone induces regression of coronary atherosclerotic plaques in patients with type 2 diabetes mellitus or impaired glucose tolerance: a randomized prospective study using intravascular ultrasound. Int J Cardiol. 138:157-165

11. Kanazawa I et al (2010) Baseline atherosclerosis parameter could assess the risk of bone loss during pioglitazone treatment in type 2 diabetes mellitus. Osteoporos Int 21:2013-2018

12. Mazzone T et al (2006) Effect of pioglitazone compared with glimepiride on carotid intima-media thickness in type 2 diabetes: a randomized trial. J Am Med Assoc. 296:2572-2581

13. WHO. Non-communicable diseases fact sheet. Public Heal An action Guid Improv Heal. (2018). doi:https://doi.org/10.1093/acprof:oso/9780199238934. 003.15

14. Moher D, Liberati A, Tetzlaff J, Altman DG (2009) Preferred reporting items for systematic reviews and meta-analyses: the PRISMA statement. J Clin Epidemiol. https://doi.org/10.1016/j.jclinepi.2009.06.005

15. Higgins JPT et al (2011) The Cochrane Collaboration's tool for assessing risk of bias in randomised trials. BMJ. https://doi.org/10.1136/bmj.d5928

16. Koshiyama H, Shimono D, Kuwamura N, Minamikawa J, Nakamura Y (2001) Inhibitory effect of pioglitazone on carotid arterial wall thickness in type 2 diabetes. J Clin Endocrinol Metab. 86:3452-3456

17. Nozue T et al (2012) Impact of diabetes mellitus on coronary atherosclerosis and plaque composition under statin therapy - subanalysis of the TRUTH study. Circ J. 76:2188-2196

18. Dormandy JA et al (2005) Secondary prevention of macrovascular events in patients with type 2 diabetes in the PROactive Study (PROspective pioglitAzone Clinical Trial in macroVascular Events): a randomised controlled trial. Lancet 366:1279-1289

19. Liu, Xiaojie et al (2017) "Comparison of Antidiabetic Medications during the Treatment of Atherosclerosis in T2DM Patients." Mediators of inflammation 2017: 5032708. https://doi.org/10.1155/2017/5032708

20. Sterne JAC et al (2019) RoB 2: a revised tool for assessing risk of bias in randomised trials. BMJ:14898. https://doi.org/10.1136/bmj.14898

21. Akinola OB, Dosumu OO, Sanusi SA, Ajayi TF, Olajide TH (2015) PPAR- $\gamma$ agonist pioglitazone improves semen quality and testicular histomorphometrics with partial reversal of hyperglycaemia in alloxaninduced diabetic rats. Middle East Fertil Soc J. 20:271-279

22. Libby P (1996) Atheroma: more than mush Lancet 348:1006-1012

23. Kisseleva T, Brenner DA (2006) Hepatic stellate cells and the reversal of fibrosis. J Gastroenterol Hepatol (Australia). https://doi.org/10.1111/j.14401746.2006.04584.x

24. Erbel $\mathrm{C}$ et al (2014) A human ex vivo atherosclerotic plaque model to study lesion biology. J Vis Exp. https://doi.org/10.3791/50542

25. Ersoy M, Selcuk Duru HN, Elevli M, Ersoy O, Civilibal M (2015) Aortic intimamedia thickness and mean platelet volume in children with type 1 diabetes mellitus. Iran J Pediatr. 25:1006-1012

26. Sabatino L, Fucci A, Pancione M, Colantuoni V (2012) PPARG epigenetic deregulation and its role in colorectal tumorigenesis. PPAR Res. https://doi. org/10.1155/2012/687492

27. Higashi $\mathrm{K}$ et al (2010) Additive antifibrotic effects of pioglitazone and candesartan on experimental renal fibrosis in mice. Nephrology. https://doi. org/10.1111/j.1440-1797.2009.01253.x

28. Kardassis D, Gafencu A, Zannis VI, Davalos A (2015) Regulation of HDL genes: transcriptional, posttranscriptional, and posttranslational. Handb Exp Pharmacol 224:113-179

\section{Publisher's Note}

Springer Nature remains neutral with regard to jurisdictional claims in published maps and institutional affiliations. 